Gerión. Revista de Historia Antigua

ISSN: 0213-0181

http://dx.doi.org/10.5209/GERI.59922

\title{
Territorios militares en Hispania: nuevas perspectivas
}

\author{
Ángel Morillo Cerdán ${ }^{1}$; Rosalía María Durán Cabello²
}

Recibido: 21 de agosto de 2017 / Aceptado: 6 de noviembre de 2017

Resumen. Los documentos epigráficos relativos a los límites de distritos militares no suelen ser muy habituales, aunque el conjunto procedente del norte de la Península Ibérica es el más numeroso de todo el Imperio. Se conocen cerca de 30 inscripciones relativas a la legio IIII Macedonica, a la legio X gemina y a la cohors IV Gallorum. Presentaremos en este trabajo un estado de la investigación sobre los territorios militares en Hispania. Es preciso definir los rasgos propios de estos distritos que circundan los campamentos romanos, que se encuentran bajo el control directo del ejército desde el punto de vista económico y jurisdiccional. Las excavaciones realizadas durante los años 2000-2001 al sureste de la ciudad de León, al otro lado del río Torío y junto al actual barrio de Puente Castro nos han permitido identificar una nueva aglomeración secundaria o vicus, denominado Ad Legionem, surgido a 2,2 km de distancia del campamento legionario de la legio VII gemina y en estrecha relación de dependencia respecto a éste. A partir de la existencia de este vicus militar satélite podemos plantear que también en el caso de Hispania se verifica la existencia de la leuga, franja de territorio de un radio de 1,5 millas (2,2 km), bajo jurisdicción militar.

Palabras clave: arqueología militar; territorium; prata; vicus; aglomeración secundaria; campamento legionario.

\section{[en] Military territories in Hispania: New perspectives}

\begin{abstract}
Epigraphic documents concerning military territorial limits are not very common, although the set from the north of the Iberian Peninsula is the largest in the Empire. We know about 30 entries concerning the legio IIII Macedonica, the legio X gemina and the cohors IV Gallorum. We present in this paper a state of research on the military territories in Hispania. It is necessary to define the features of these districts surrounding the Roman camps, which are under the direct control of the army from the economic point of view and jurisdictional. Excavations during the years 2000-2001 southeast of the city of Leon, across the Torío river and next to the current district of Puente Castro have allowed us to identify a new secondary agglomeration or military vicus so-called Ad Legionem. This arises 2,2 km from the legionary camp of legio VII gemina at Leon and in close dependence on it. From the existence of this military vicus satellite we can argue that even in the case of Hispania verified the existence of the leuga, strip of land within 1,5 miles $(2,2 \mathrm{~km})$ under military jurisdiction.
\end{abstract}

\footnotetext{
$1 \quad$ Universidad Complutense de Madrid.

E-mail: amorillo@ghis.ucm.es

2 Universidad Complutense de Madrid.

E-mail: roduran@ghis.ucm.es
} 
Keywords: Military archeology; Territorium; Prata; Vicus; Secondary agglomeration; Legionary camp.

Sumario: 1. Epigrafía de los límites y epigrafía del territorio militar. 2. Territorio militar o territorio militarizado: problemas de definición. 3. La leuga, un nuevo tipo de demarcación territorial de carácter militar: el ejemplo del vicus militar de Ad Legionem. 4. Algunas consideraciones finales. 5. Referencias bibliográficas.

Cómo citar: Morillo Cerdán, Á.; Durán Cabello, R. Ma (2017): Territorios militares en Hispania: nuevas perspectivas, en Gerión 35(2), 511-536.

\section{Epigrafía de los límites y epigrafía del territorio militar}

La incorporación paulatina de nuevos territorios provinciales por parte de Roma llevó a una profunda transformación de sus estructuras, a fin de afianzar los mecanismos de control social y económico por parte de la potencia colonizadora. Ese proceso llevaba implícita la creación de una nueva organización territorial, basada en la explotación de los recursos disponibles, uno de cuyos mejores ejemplos lo encontramos en la Península Ibérica, y que queda refrendado por la disposición de unidades militares (Fig. 1). Un procedimiento de este tipo exigía una delimitación física de los territorios asignados tanto al Estado como a los nuevos municipios o civitates. La demarcación se establece a partir de hitos naturales en el paisaje -ríos, arroyos, montes, caminos, etc.-; (per demonstrationes finium), mientras que en otras ocasiones es necesaria una intervención mediante documentos epigráficos (termini). Esta última actuación es denominada limitatio. ${ }^{3}$

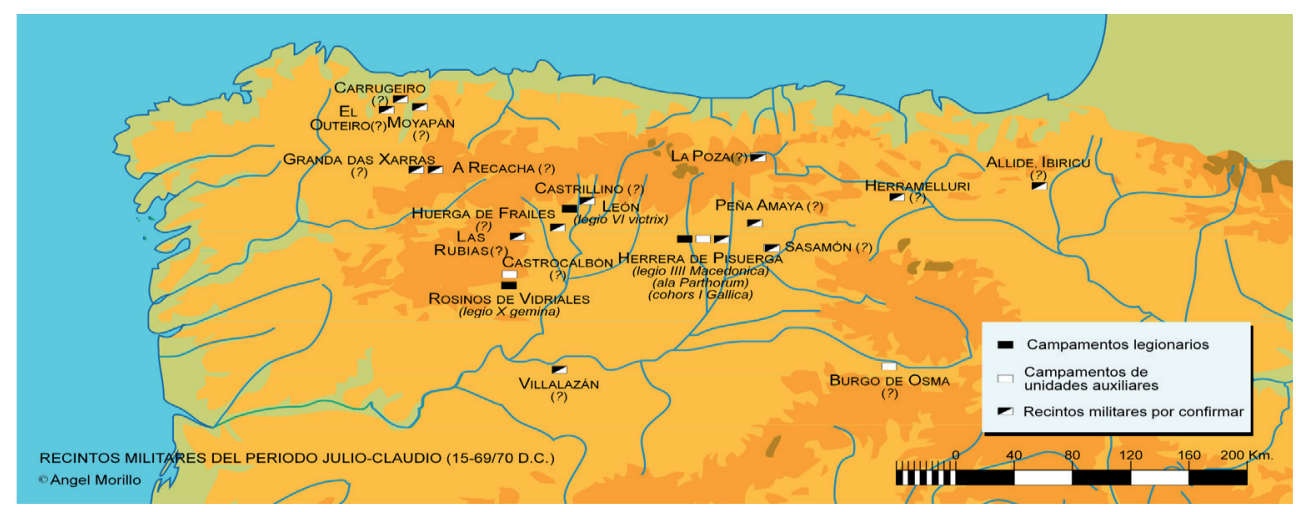

Figura 1. Campamentos romanos en el norte y noroeste de la Península Ibérica durante el periodo julioclaudio (Á. Morillo).

Orejas 2003, 400-401. 
A partir de trabajos de referencia como el de Le Roux, ${ }^{4}$ durante los últimos años se han dado a conocer varias revisiones sobre la epigrafía de los límites de las ciudades romanas en Hispania, ${ }^{5}$ además de varios documentos inéditos. ${ }^{6}$ Pero sin duda ha sido Cortés Bárcena quien, en una reciente monografía, ha presentado un estudio más completo al respecto.?

Dentro del repertorio conocido de hitos de delimitación hispanos, los más frecuentes deslindan el territorio de ciudades de diferente categoría jurídica. Los documentos epigráficos relativos a los límites de distritos asignados a unidades militares no suelen ser muy habituales, aunque el conjunto procedente del norte de la Península es el más numeroso de todo el Imperio, constituyendo una anomalía que aún no ha sido bien explicada a pesar de los intentos en este sentido. Fuera de nuestras fronteras se conocen dos ejemplares procedentes de Dalmacia hallados en las cercanías de Burnum, base de la legio XI Claudia, uno de los cuales, datado a mediados del siglo I d.C. alude directamente a esta unidad. Un testimonio más se ha recogido en Moesia Inferior, en la que un tribuno de una cohorte se refiere a los límites de unos prata publi$\mathrm{ca}$. Finalmente un cuarto ejemplar, datado a finales del siglo II o comienzos del III, en el que se menciona a la legio I Minervia, procede de Germania Inferior. Otro epígrafe, en este caso votivo, en el que se mencionan prata militares, fue hallado en Pannonia. ${ }^{8}$

Frente a este repertorio documental tan escaso, la Hispania Citerior, en concreto los conventus Cluniensis y Asturum han proporcionado una treintena de hitos de demarcación de este tipo, constituidos por dos conjuntos principales, uno relativo a la legio IIII Macedonica, y otro concerniente a la cohors IV Gallorum. El empleo de la piedra en este caso, en lugar de otros materiales como la madera que también debieron emplearse para la terminatio, indica bien a las claras una dimensión propagandística añadida. ${ }^{9}$

El caso mejor documentado, ya dado a conocer por García y Bellido, ${ }^{10}$ es el de los llamados hitos augustales, mojones de demarcación de los campos de la Legión IV Macedónica, asentada en Herrera de Pisuerga ${ }^{11}$ (Fig. 2). Se conservaban 18 ejemplares que delimitaban los prata legionarios respecto al ager del municipio de Iuliobriga (Retortillo, Campoo de Enmedio, Cantabria). Su hallazgo se concentra en una zona muy reducida de unos $16 \mathrm{~km}$ de perímetro, rodeando el valle del río Camesa, al sur de Cantabria, junto al límite provincial con Palencia ${ }^{12}$ y a unos $12 \mathrm{~km}$ al sur de la ciudad romana de Iuliobriga. Recientemente se ha dado a conocer un nuevo ejemplar fragmentario procedente de La Cuadra (Valdeolea), en la misma zona que los anteriores. ${ }^{13}$

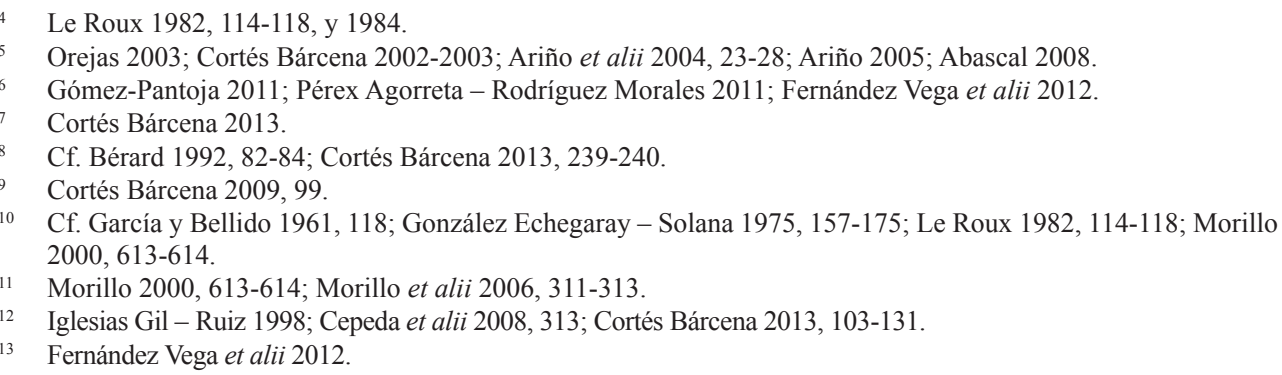




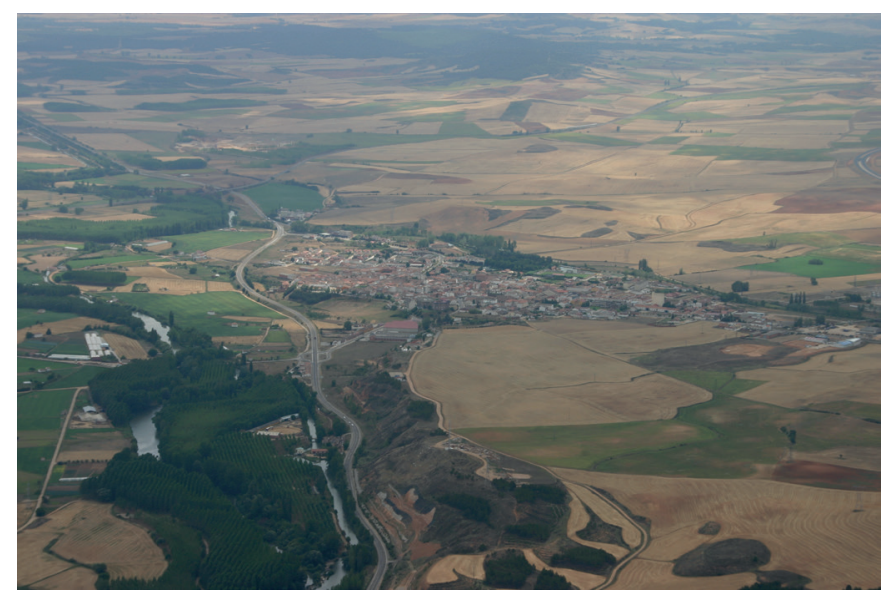

Figura 2. Fotografía aérea de la localidad palentina de Herrera de Pisuerga, asentamiento de la legio IIII Macedonica (20/15 a.C. y el 39 d.C.), en el que se percibe claramente su posición topográfica en el interfluvio del Pisuerga, a la izquierda, y el Burejo, a la derecha (Á. Morillo).

El conjunto se talló en grandes lajas de arenisca para ser enterradas parcialmente. Es muy homogéneo, lo que indica que se elaboró en el mismo momento. ${ }^{14} \mathrm{La}$ fórmula epigráfica es siempre la misma, aunque las abreviaturas y nexos varían ligeramente: terminus Augustalis dividit prata legionis IIII et agrum Iuliobrigensium (Fig. 3). Otro ejemplar, procedente en esta ocasión de Villasidro (Burgos), cerca de la actual localidad de Sasamón, establece los límites entre los prata de la legión y el ager del municipium Segisamonensium (CIL II 5807).

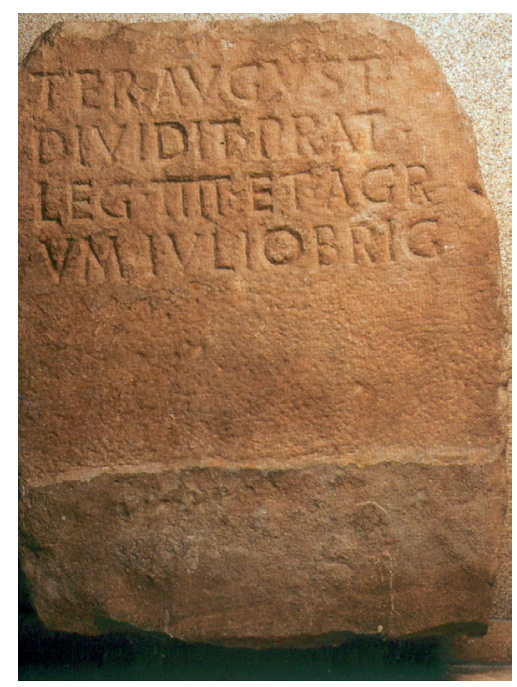

Fig. 3. Hito augustal de Valdeprado del Río o Valdeolea, en el que se mencionan los prata de la legio IIII Macedonica y su demarcación respecto a la ciudad de Iuliobriga (Museo Regional de Arqueología de Cantabria).

$14 \quad$ Morillo 2000, 614. 
Los hitos augustales de demarcación de los campos de la legión IV Macedónica han generado en la bibliografía una amplia polémica tanto sobre la extensión del territorio militar, como sobre la cronología de los mismos (Figs. 4 y 5). Respecto a su cronología, teniendo en cuenta que se invoca únicamente a la autoridad imperial bajo el nombre de terminus Augustalis, no cabe duda que el único elemento de datación disponible es la propia fundación de Iuliobriga y Segisamo, ambas comunidades de derecho latino a juzgar por la propia fórmula epigráfica que aparece en los hitos augustales para referirse a su territorio: ager. ${ }^{15}$

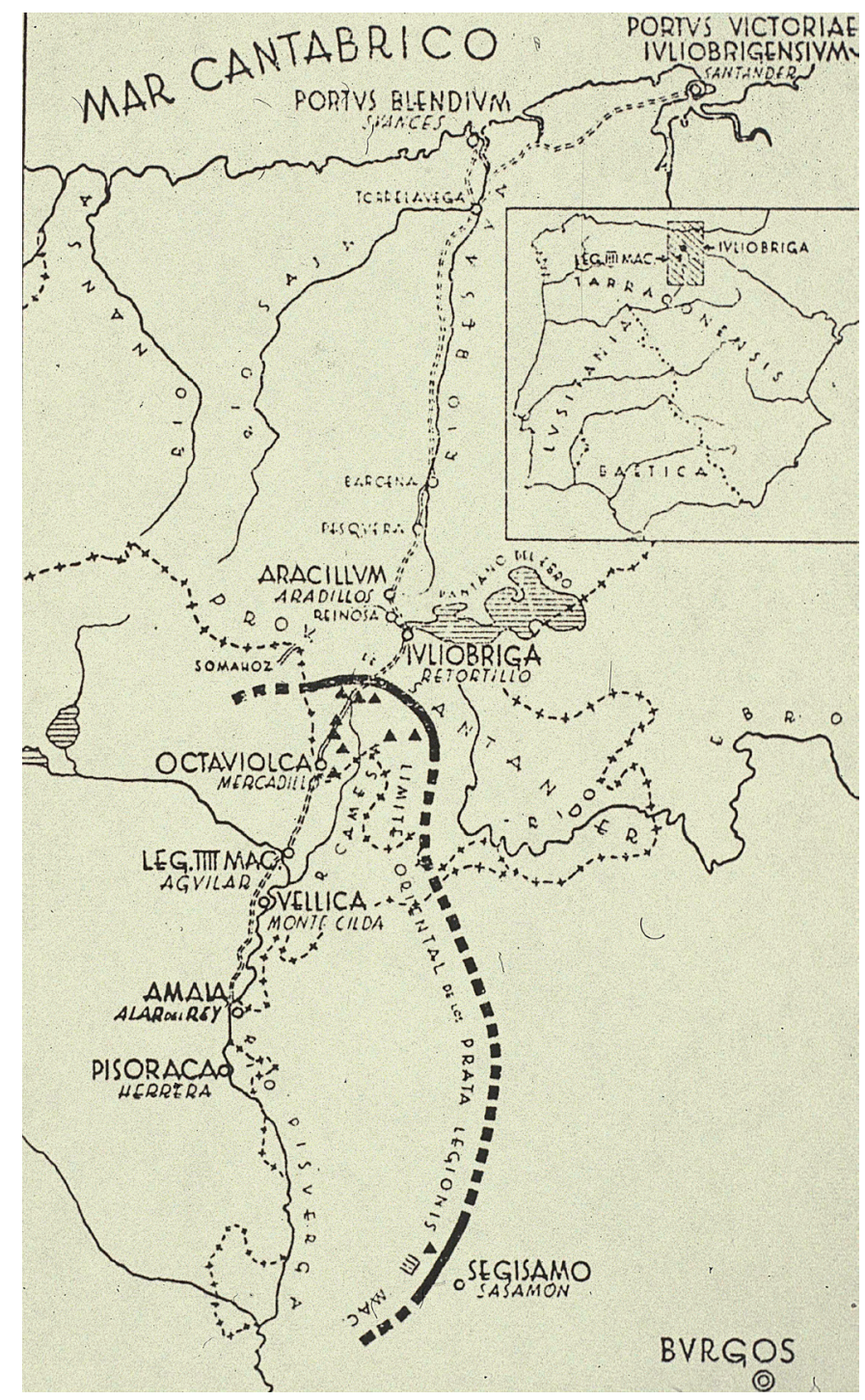

Figura 4. Extensión de los hitos terminales de la legio IIII Macedonica según García y Bellido (1956).

Abascal 2008, 79-80. 


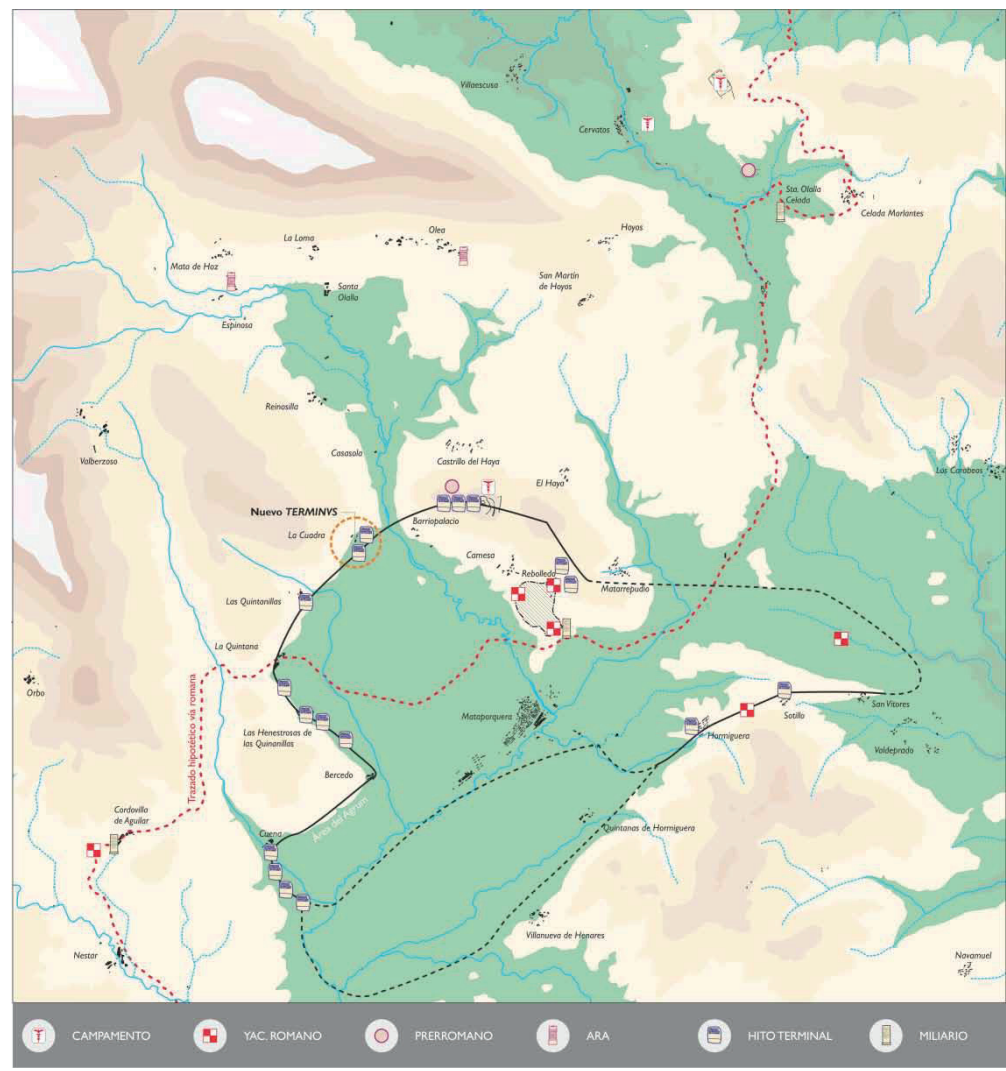

Figura 5. Ubicación de los hitos terminales de la legio IIII Macedonica en el valle del río Camesa indicando la posición del nuevo hito de La Cuadra (Valdeolea).

(Fernández Vega et alii 2012, fig. 4).

Por lo que se refiere a Iuliobriga, la opinión más difundida es la que remonta la fundación de la ciudad a un momento inmediatamente posterior a las Guerras Cántabras, en torno al 15 a.C. ${ }^{16}$ Dicha cronología no encuentra por el momento apoyo alguno en los restos materiales proporcionados por el yacimiento, todos ellos posteriores al cambio de Era. ${ }^{17}$ Obviamente, no es preciso delimitar las tierras de la legión mientras no existiera dicho municipio, por lo que la propia fundación, sea cuando fuere, constituiría la fecha post quem para la colocación de los mojones de delimitación. Abascal ha apuntado el tercer viaje de Augusto a la Península Ibérica, entre el 15 y el 13 a.C., como el momento más apropiado para establecer los criterios de tributación para las comunidades y reorganizar sus territorios estableciendo sus límites. Esto le lleva a datar la promoción jurídica de Iuliobriga en el 15 a.C. Por lo tanto, esta sería supuestamente la datación de los términos augustales que separaban los prata de la legio IIII Macedonica de Iuliobriga. Sin embargo, este mismo autor reconoce que la fecha de la decisión jurídica no es necesariamente la fecha en que esta se expresaría de forma epigráfica. ${ }^{18}$ 


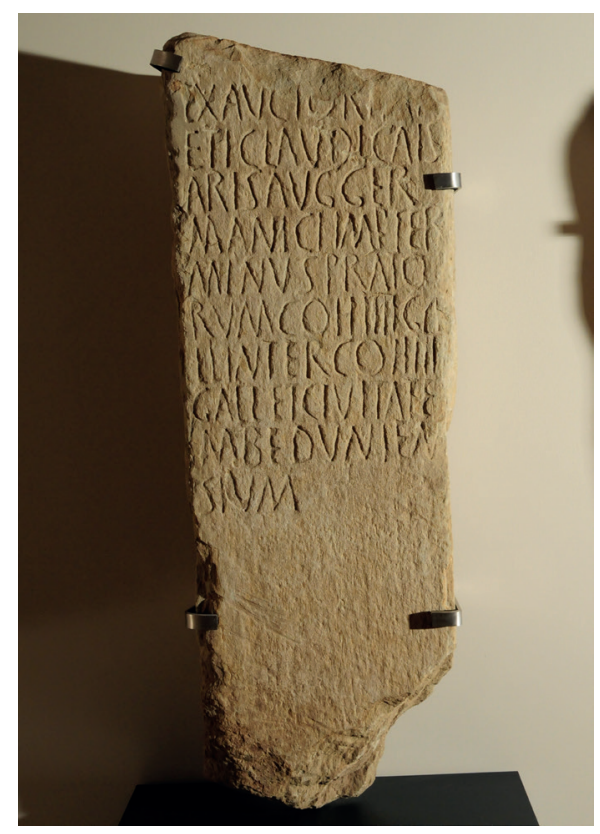

Figura 6. Hito augustal de delimitación del territorio de la cohors IIII Gallorum y la civitas Baeduniensium, procedente de Soto de la Vega (o Santa Colomba de la Vega). Museo de León (Á. Morillo).

Por lo que respecta a Segisamo, carecemos también de datos sobre su fundación, que no debe estar muy alejada en el tiempo de la de Iuliobriga. Carece por completo de fundamento la hipótesis sobre la antecedencia temporal del hito de Villasidro, muy alejado del grupo principal, antecedencia que supuestamente convertiría dicho epígrafe en un testimonio del campamento de las guerras cántabras establecido por Augusto junto a Segisama. Los restantes, que demarcarían los prata legionarios respecto a Iuliobriga, serían de época tiberiana. ${ }^{19}$ En realidad, ninguna diferencia epigráfica ni cronológica puede establecerse entre el hito de Villasidro, que separa los prata de la legión del territorio segisamonense, y los hitos restantes.

Una cuestión sobre la que debemos reflexionar, tanto en este caso de los hitos augustales de la legio IIII, como en el del segundo conjunto de hitos que analizaremos más adelante, las unidades militares son mencionadas en primer lugar, luego lo que parece estarse delimitando es el territorio adscrito a éstas, no a las ciudades. Si la legio IIII Macedonica estaba asentada en Herrera de Pisuerga desde el 19 a.C., y Iuliobriga se funda algunos años más tarde, no tendría sentido deslindar el territorio de la unidad respecto al de la ciudad, sino que lo lógico hubiera sido a la inversa, deslindar el ager asignado en ese momento a la colonia respecto al de la unidad militar. Por lo tanto, hay una adaptación a una organización territorial preexistente. Los hitos podrían haberse tallado y colocado años más tarde, como hemos planteado con anterioridad, ${ }^{20}$ tal vez en relación con la modificación de la política militar aplicada a Hispania que tiene lugar a finales del reinado de Augusto o comienzos del de Tiberio, cuya manifestación más

9 González Echegaray - Solana 1975, 192-193.

20 Morillo 2000, 614. 
visible es la propia reestructuración de los campamentos legionarios, buscando una mayor estabilidad, ${ }^{21}$ además de la racionalización del abastecimiento militar. ${ }^{22}$

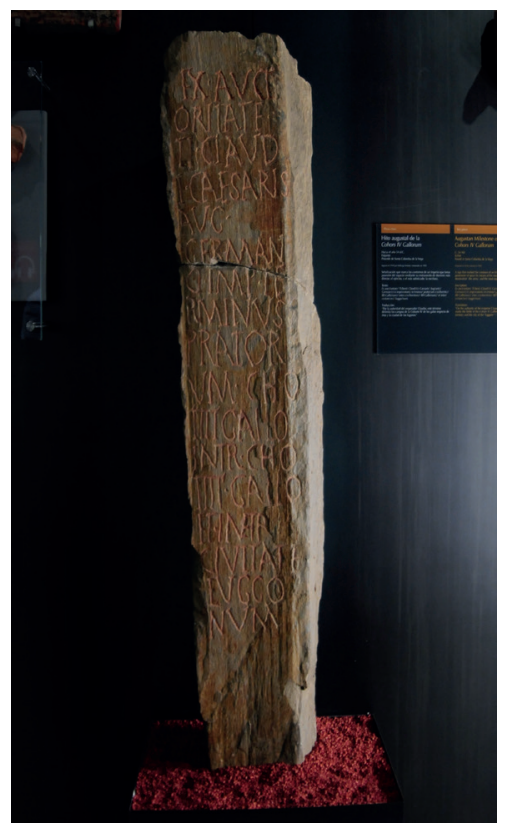

Figura 7. Hito augustal de delimitación del territorio de la cohors IIII Gallorum y la civitas Luggonum, procedente de Soto de la Vega (o Santa Colomba de la Vega). Museo de León. (Á. Morillo).

El segundo conjunto en importancia de hitos terminales de carácter militar fue hallado al sur de la actual provincia de León. En ellos se deslindan los prata de la cohors IV Gallorum respecto a las civitates de los Baedunienses (5 epígrafes) y Luggoni (2 epígrafes). Dos piezas muy fragmentarias pertenecen al mismo grupo, si bien el texto conservado no permite determinar respecto a qué civitas se demarcaban los campos de la cohorte. ${ }^{23}$ Salvo uno de ellos, hallado en las cercanías de Castrocalbón, el resto procede supuestamente de Soto de la Vega, aunque recientemente se ha apuntado que su procedencia real es una localidad cercana, Santa Colomba de la Vega, en el término del Espino, donde aparecieron amontonados o enterrados, seguramente tras ser retirados de su posición originaria. ${ }^{24}$

El conjunto también es muy semejante, lo que indica que los hitos se elaboraron siguiendo una misma plantilla en un único taller. ${ }^{25}$ La fórmula epigráfica también es sencilla:

Ex auctoritate Tiberii Claudii Caisaris Augusti Germanici Imperatoris terminus pra-

\footnotetext{
21 Morillo 2002, 83-86.

22 Morillo 2006, 52-57.

23 García y Bellido 1961, 155-159; Roldán 1974, 439-440; Rabanal - García Martínez 2001, 339-346, n 305-314; Cortés Bárcena 2013, 85-100.

24 Mangas 2008, 89-90.

25 Le Roux 1982, 114.
} 
torum cohortis IIII Gallorum inter Cohortem IIII Gallorum et civitatem Baeduniensium et civitatem Luggonum (Figs. 6 y 7).

En dos casos se indica la distancia respecto a otro hito, que se indica en passus, seguramente porque el paisaje no permitía ver con claridad donde se encontraba la siguiente linde. ${ }^{26}$

La mención al nombre del emperador Claudio, de cuya autoridad dimana el deslinde, no deja lugar a dudas en este caso sobre su datación. Por otra parte, tanto la invocación a la autoridad imperial como el término empleado para referirse a las ciudades, que en este caso no es ager, sino directamente se alude a su carácter de civitas, término que en sí mismo lleva implícita una dimensión territorial, indica que estamos ante ciudades no privilegiadas, por lo que no era necesario una segregación jurisdiccional, puesto que su ager es todavía ager populi Romani. ${ }^{27}$

Si en este caso la cronología no deja lugar a dudas, las circunstancias del hallazgo del conjunto y el desconocimiento sobre el emplazamiento del castellum de la cohors IV Gallorum dejan planteadas incluso más incógnitas que en el caso anterior. Loewinsohn atribuye a dicha cohorte los campamentos localizados en Castrocalbón, ${ }^{28}$ a pesar de que por el momento carecemos de evidencias. ${ }^{29} \mathrm{La}$ reducción de $B e d u n i a^{30}$ con el castro de San Martín de Torres (Cebrones del Río, León), en la ribera derecha del Órbigo, no ofrece por el momento duda alguna. ${ }^{31}$ Esta aglomeración secundaria apenas está documentada desde el punto de vista arqueológico, si bien subsisten huellas de un urbanismo desarrollado, así como restos materiales de todo tipo. Algunas evidencias podrían indicar que, al igual que sucede en numerosas ocasiones en el ámbito de la Meseta, el castro de San Martín de Torres correspondería tal vez al establecimiento prerromano, más tarde romanizado. La ocupación romana se extendería también al pie de la vertiente oriental del castro, por donde debería discurrir la vía romana.

Mayores problemas presenta la civitas Luggonum, comenzando por el propio hecho de que parecen existir dos etnias homónimas según recoge Ptolomeo, una al norte de la Cordillera Cantábrica, al oriente de Asturias, mientras otra se situaba al sur, cerca de la capital del conventus Asturum. Los dos hitos de demarcación que separan los prata de la cohors IV y la civitas Luggonum son las únicas referencias a la existencia de dicha civitas. Uno de los núcleos principales de los Luggones meridionales parece ser Argentiolum, citada por Ptolomeo ${ }^{32}$ y mencionada en una de las Tablas de Barro de Astorga, ${ }^{33}$ que se sitúa sin demasiadas dudas en el yacimiento de San Miguel, en Viñambres de la Valduerna (León), ${ }^{34}$ o en el cercano pago de El Campo del Medio (Villamontán de la Valduerna). Tal vez esta sea la que los hitos augustales señalan como civitas de los Luggones. ${ }^{35}$

Si partimos de las ubicaciones conocidas, el lugar ocupado por la antigua Bedunia, San Martin de Torres, se encuentra a unos 5 km del lugar de hallazgo del depó-

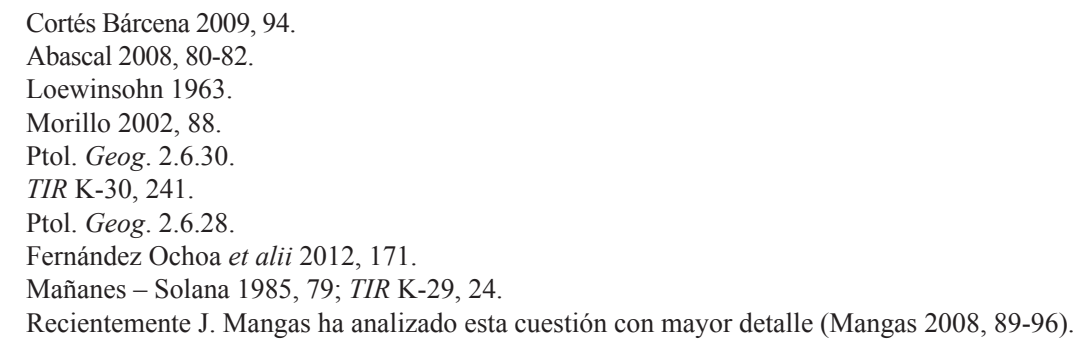


sito de hitos en Santa Colomba de la Vega (Fig. 8). Pero el único mojón hallado aparentemente in situ se halló en Castrocalbón, a unos 12 km de San Martín de Torres, a orillas del Eria. Probablemente, y teniendo en consideración el carácter del territorio deslindado, prata, los hitos debieron disponerse en algún lugar de las fértiles vegas del Órbigo o Eria.

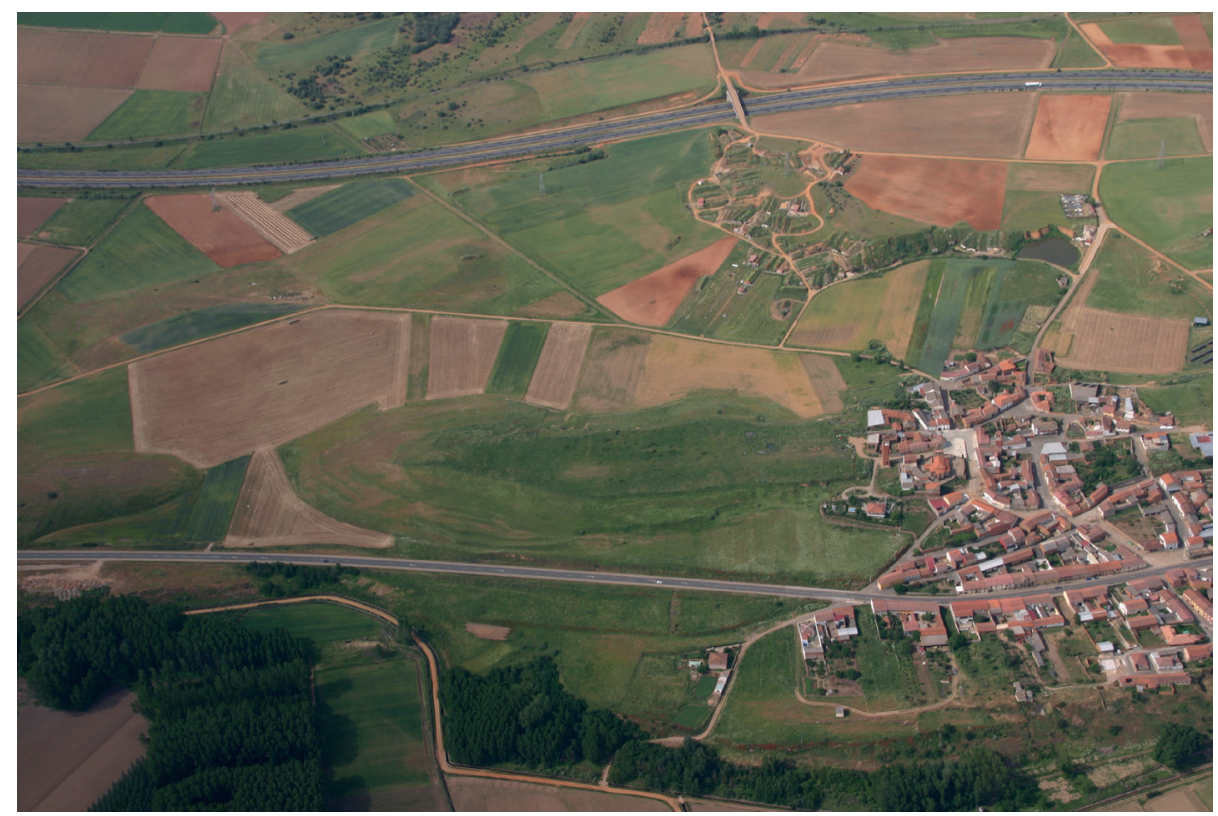

Figura 8. Fotografía aérea del castro de San Martín de Torres, la antigua Bedunia (Á. Morillo).

La situación se complica aún más si consideramos el último hallazgo de epigrafía militar relativa a límites territoriales, que procede de la misma zona. En Quintana y Congosto (León), situado a poca distancia de Castrocalbón, pero también muy cerca de San Martín de Torres (León), la antigua Bedunia, apareció un hito de demarcación de los campos de la legio X gemina respecto a los de dicha civitas. ${ }^{36} \mathrm{La}$ fórmula empleada es casi idéntica a los anteriores: Ex auctoritate Tiberii Claudii Caisaris Augusti Germanici Imperatoris terminus pratorum legionis X decimae Geminae inter legionem decimam et civitatem Baeduniensium (Fig. 9).

En esta ocasión podemos situar los respectivos epicentros del territorio demarcado. Ya hemos señalado anteriormente la posición de Bedunia. Por lo que se refiere al campamento de la legio X gemina, sabemos que dicha unidad se acantona en Rosinos de Vidriales (Zamora). El establecimiento de la legión X en este lugar está avalado por la presencia de un gran recinto rectangular con esquinas redondeadas, de unas 17,5 ha, que parece contar con un potente muro realizado con bloques de cuarcita y argamasa y un doble foso en algunos de sus lados, además de diversos testimonios epigráficos sobre lápidas y tejas. ${ }^{37}$ El conocimiento de este acantonamiento se ve entorpecido por la presencia de un campamento superpuesto, que fue

6 Descosido 1982; Rabanal - García Martínez 2001, 346-348, nº 315.

37 Martín Valls et alii 1975; Wahl 1984; Carretero - Romero Carnicero 1996, 9-21; Carretero 2006, $171-177$. 
construido a fines del siglo I por una unidad auxiliar, el ala II Flavia Hispanorum civium Romanorum $^{38}$ (Fig. 10).

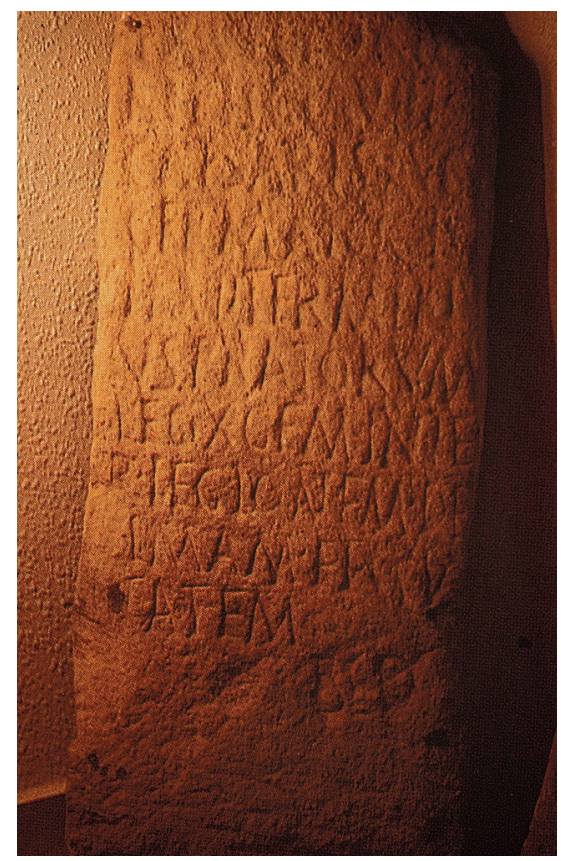

Figura 9. Término augustal de separación entre el territorio de la legio X gemina y la civitas Bedunia, Quintana y Congosto, León (J. A. Arranz Mínguez).

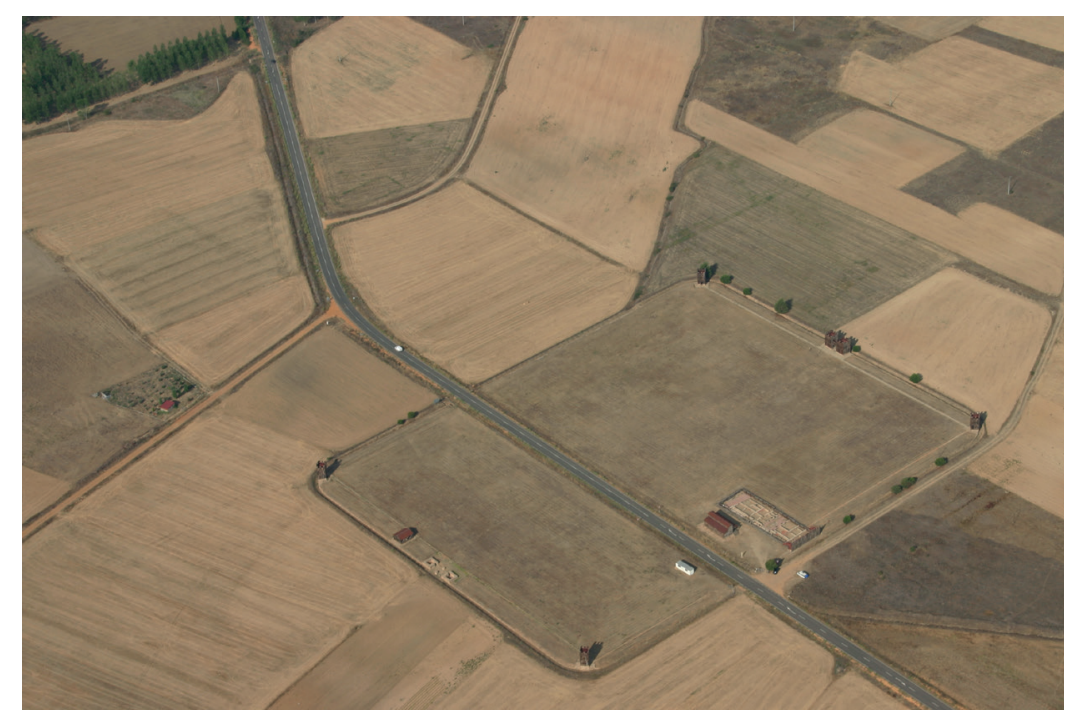

Figura 10. Fotografía aérea del campamento del ala II Flavia en Rosinos de Vidriales (Á. Morillo).

38 Carretero 2000. 
La fecha en que tiene lugar el estacionamiento de la legio X gemina en Rosinos dista mucho de estar aclarada convenientemente, ya que el registro arqueológico correspondiente al periodo más antiguo permanece por el momento inédito. Los investigadores dataron en un primer momento la fundación del campamento durante las Guerras Cántabras. ${ }^{39}$ Carretero y Romero Carnicero lo retrasan hasta el 20/15 a.C., una vez terminada la contienda ${ }^{40} \mathrm{Sin}$ embargo, estos mismos autores ya señalan que el patrón material más antiguo es en su mayoría posterior al cambio de Era y su mayor concentración arranca del reinado de Tiberio. Recientemente se ha señalado que el registro correspondiente a la legio X gemina, conocido a través de dos sondeos y datado entre el 10 a.C. y el 70 d.C., se podría dividir en dos subfases, una tardoaugustea-tiberana y otra claudio-neroniana ${ }^{41}$

Por nuestra parte, y a reserva de que nuevas publicaciones pudieran modificar este panorama, planteamos que la fundación del recinto militar de Rosinos debe retrasarse hasta el periodo tiberiano, coincidiendo con la partida de Astorga de los efectivos de la legio X gemina. Sin embargo, no podemos descartar completamente la convivencia de los recintos campamentales de Astorga y Rosinos durante algunos años, aunque esta hipótesis implicaría la existencia de una fase constructiva más antigua en el recinto militar de Rosinos, que hasta hoy no conocemos. ${ }^{42}$

Por otra parte, la petrificación de estructuras defensivas en recintos militares romanos no se documenta hasta mediados del siglo I d.C. y no se aplica a campamentos legionarios hasta época flavia, momento de reedificación de numerosos recintos en Germania tras la revuelta bátava de Civilis. La existencia de una muralla de piedra en Rosinos constituiría un unicum en contextos augusteos o julio-claudios, por lo que debemos postular al menos una segunda fase constructiva en dicho acantonamiento, a la que correspondería la muralla pétrea. A favor de esta interpretación hablaría asimismo el carácter estrictamente regular del recinto defensivo, planta que aún no ha alcanzado su pleno desarrollo en los campamentos renanos del periodo augusteo y que debe estandarizarse a partir de los reinados de Claudio y Nerón. ${ }^{43}$

El momento final del campamento coincidiría con la partida de la legio X gemina hacia Carnuntum en el año 63 d.C. Dicha unidad regresó a Hispania para una breve estancia entre el 68 y el 70 d.C., y existen ciertos indicios de que volvió a ocupar su antiguo campamento en Rosinos de Vidriales. Tal vez a este momento corresponde el abundante material latericio con marca legionaria. ${ }^{44}$

De cualquier modo, no cabe duda que la legio X gemina se encontraba asentada en Rosinos de Vidriales durante el reinado de Claudio, fecha en que se talló el hito de demarcación respecto a Bedunia. Sin embargo, la aparente coincidencia temporal en un mismo espacio físico de dos unidades militares, una legionaria y otra auxiliar, que demarcan sus prata respecto a Bedunia no deja de plantear cuestiones de difícil respuesta. Que una unidad auxiliar, la cohors IIII Gallorum, procediera a delimitar epigráficamente sus campos distinguiéndolos de los de su más que probable unidad matriz, la legio X gemina, plantea problemas jurisdiccionales. Por otra parte la co-

\footnotetext{
Martín Valls et alii 1975, 6.

40 Carretero - Romero Carnicero 1996, 9-21; Carretero 2006, 171-177.

${ }_{41}$ Blázquez Cerrato - Carretero 2006, 195, n. 1.

42 Morillo 2002, 84.

43 Morillo - Salido 2013, 290-291.

44 Wahl 1984, 73-74; Morillo - Salido 2013, 314.
} 
hors $I V$ es la única unidad auxiliar que demarca territorios en todo el Imperio, lo que no nos permite establecer comparaciones con otras zonas. Tampoco parece probable que la demarcación sea sucesiva durante el reinado de Claudio, puesto que legio $X$ gemina estaba ya asentada en la zona desde el periodo tiberiano, y la única referencia a la cohorte IV son precisamente los hitos terminales. Si a esto le añadimos el sorprendente desconocimiento arqueológico del campamento donde debió instalarse la cohors IIII de una forma más o menos estable, a juzgar por el propio procedimiento de demarcación territorial que le afecta, y el hallazgo de casi todos los hitos juntos, aparentemente tras ser retirados. Pero tal vez dichos hitos nunca fueron colocados en el lugar previsto, ${ }^{45} \mathrm{y}$ la instalación de dicha unidad militar en la región fue una operación fallida que jamás llegó a cristalizar. ${ }^{46}$

No deja de llamar la atención que, por el momento, ni el campamento de la legio $X$ gemina en Astorga, ni los de la legio VI Victrix y la legio VII gemina en León han proporcionado noticia alguna de la existencia de prata en sus cercanías. Tal vez en estos dos casos, y siguiendo la hipótesis formulada por Groenman-van Waateringe, ${ }^{47}$ el entorno civil estaba lo suficientemente desarrollado como para proporcionar suministros a la intendencia militar, lo que hacía innecesario segregar una zona y colocarla bajo la autoridad del ejército para el suministro de determinados productos. ${ }^{48} \mathrm{O}$ tal vez estamos ante la ausencia de comunidades lo suficientemente cercanas como para necesitar una terminatio. Por no hablar de un simple problema de documentación arqueológica.

\section{Territorio militar o territorio militarizado: problemas de definición}

En realidad, la interpretación de los hitos de delimitación de los prata de las unidades militares, forma parte de una cuestión mucho más amplia y compleja, como es la delimitación y la propia existencia de territorios militares stricto sensu.

La primera cuestión es aclarar el significado del término prata. El propio vocablo tiene un carácter restrictivo, ya que no alude a tierras de cultivo, sino a pastos, evidentemente para los caballos y los rebaños que abastecían de carne, leche, cuero y lana a las tropas. ${ }^{49}$ Seguramente otras materias primas como arcilla, madera o paja, procedían de este territorio, donde podían tener lugar otras actividades como la caza y maniobras militares.

El abastecimiento de las tropas, tanto si se encontraban en campaña como asentadas en campamentos permanentes, constituía un problema de primer orden para la administración militar romana. El ejército organiza una amplia red de suministros básicos con destino a las diferentes unidades militares, que abarca tanto artículos de primera necesidad como productos manufacturados, tanto importados como locales. Habida cuenta de los elevados costes del transporte a larga distancia se suele preferir

45 García y Bellido 1961, 150-155.

46 De cualquier forma, algunas evidencias arqueológicas que van conociéndose plantean que deben revisarse hipótesis hasta ahora aceptadas sin discusión, como la radical separación entre tropas legionarias y auxiliares por lo que se refiere al lugar de acantonamiento. Un magnífico ejemplo en este sentido es la presencia de evidencias del ala I Thracum en el campamento de la legio II Augusta en Caerleon (Zienkiewicz 1993, 27-85).

47 Groenman-van Waateringe 1997, 263.

48 Morillo 2006, 34-35.

49 Schulten 1962, 213; Mócsy 1974, 352. 
recurrir a la producción agrícola y artesanal del territorio circundante, siempre y cuando esta sea lo suficientemente desarrollada como para proveer a la intendencia militar de todo aquello que necesita mediante el comercio, los impuestos o la simple requisa ${ }^{50}$ Tan sólo en el caso de los prata testimoniados a través de la epigrafía se verifica cómo parcelas del territorio circundante a los campamentos son puestos bajo la autoridad directa del ejército para contribuir al sustento de la unidad. Aunque algún autor aislado considera que prata podría ser un término arcaizante que se mantuvo a lo largo del Imperio y que pudo designar más tarde tierras para otras funciones, ${ }^{51}$ ningún testimonio epigráfico o arqueológico permite afirmar que los prata fueran empleados como tierras de cultivo. ${ }^{52}$

Como bien señala Cortés Bárcena, la primera cuestión es aclarar si el término prata es sinónimo de territorio militar. ${ }^{53}$ García y Bellido ${ }^{54}$ considera que el término prata se refiere a la totalidad del territorio bajo jurisdicción militar. Mócsy ${ }^{55}$ y Mason $^{56}$ consideran ambos vocablos como sinónimos, si bien prata correspondería a los testimonios más antiguos, siendo sustituido desde mediados del siglo II d.C. por territorium legionis. Bien distinta es la opinión de Vittinghoff ${ }^{57}$ y Roldán, ${ }^{58}$ quienes consideran que prata es un término mucho más restrictivo que territorium, que hace referencia a áreas del territorio anteriormente pertenecientes al ager publicus o a ciudades y, por lo tanto, su sentido sería completamente distinto. Le Roux es de esta misma opinión, ${ }^{59}$ si bien considera que tanto el campamento como los campos de maniobras formaban parte de esta categoría de prata dentro del territorio asignado a una unidad.

De cualquier forma, desde el punto de vista jurídico, el ejército no es propietario de los prata asignados para su control y sustento. Dicho espacio forma parte del ager publicus, propiedad del tesoro imperial (fiscus), aunque el ejército empleaba el territorio y lo delimitaba, indicativo de un derecho de usufructo, ${ }^{60}$ y estaba exento de pagar impuestos, a diferencia de las tierras asignadas a las civitates peregrinas. Uno de los hitos hallados en Dalmacia nos ilustra incluso que las tierras asignadas a la legión seguían denominándose prata legionis aunque la unidad hubiera sido trasladada y su campamento abandonado, por lo que seguían siendo públicas, bajo la administración directa del gobernador de la provincia. Es posible que continuaran al servicio de unidades auxiliares del ejército, como podría verificarse tanto en Burnum (Dalmacia) como en los casos constatados en Hispania. ${ }^{61}$

Los partidarios de identificar los prata con el territorium militar en su conjunto llevan a plantear territorios legionarios de enorme extensión, ${ }^{62}$ que en el caso de la legión

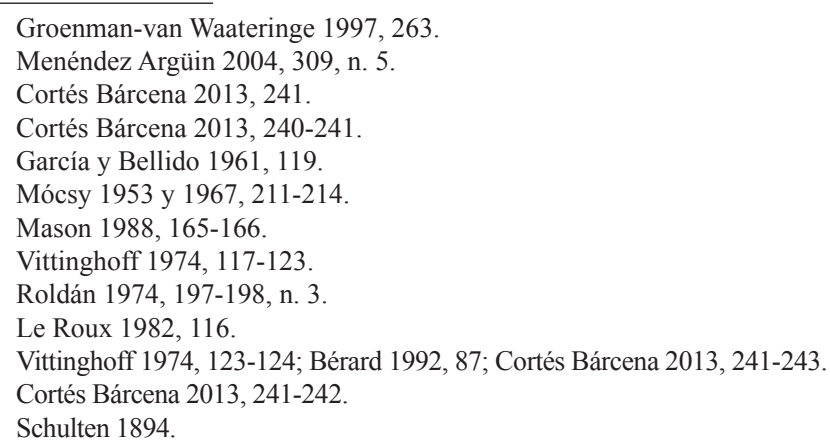


IV Macedónica llegaría a los $75 \mathrm{~km}^{2}{ }^{23}$ lo que no dejaba de plantear graves problemas de definición arqueológica, comenzando por la propia ausencia de amojonamiento en la mayor parte de esta desmesurada área. Para Roldán, que sigue a Vittinghoff, los prata se extenderían como pequeñas zonas de pasto o forrajeo dentro del radio de acción de la unidad militar, pero sin constituir un territorio continuo. ${ }^{64}$ Los prata pudieron estar distribuidos como enclaves aislados dentro de territorios asignados previamente a algunas ciudades. La gran distancia entre los hitos de la legio IIII Macedonica hallados al sur de Cantabria y el hallado en Villasidro, en la provincia de Burgos, parece apuntar al carácter discontinuo de los prata de dicha unidad legionaria. ${ }^{65}$

$\mathrm{Si}$, tal y como parece, prata no puede identificarse con territorio militar en su conjunto, nos encontramos ante una cuestión conceptual de primer orden, como es la propia existencia y definición de dichos "distritos". La epigrafía se refiere en contadas ocasiones al territorium legionis. ${ }^{66} \mathrm{Y}$ tampoco está claro que se refiera a grandes extensiones de terreno como planteaba Schulten. ${ }^{67} \mathrm{La}$ evidencia arqueológica de dicho espacio también es muy difícil de rastrear. Se ha intentado reconstruir dicho territorio a partir de la dispersión de villas rústicas de granjeros o veteranos cercanas a los campamentos, supuestamente encaminadas al abastecimiento de la unidad militar, e incluso mediante la dispersión de material latericio con marca militar ${ }^{68}$ Sin embargo tales elementos sólo nos indicarían el área de influencia económica de la unidad militar, pero no los límites jurídicos. ${ }^{69}$ Un ejemplo recientemente conocido es el de la dispersión de las marcas latericias de la legio VII gemina, que alcanzan áreas mucho más allá de la posible autoridad de la legión ${ }^{70}$ (Fig. 11).

La propia existencia de un amplio dominio territorial por parte de las unidades militares debe ponerse en cuestión. Ni poseen personalidad jurídica diferenciada, ni se puede sostener su existencia desde el punto de vista epigráfico y arqueológico, salvo que entendamos por territorio militar un distrito que rodea a los campamentos y en el que se hace patente su influencia desde el punto de vista más económico que jurisdiccional, y que debe dar lugar a respuestas algo diferentes al territorio adscrito a núcleos civiles (civitates), pero no bajo el control directo del ejército. En este sentido sería más propio hablar de territorio militarizado. Es preciso definir los rasgos propios de estos distritos, analizar los sistemas de hábitat del territorio militar, comenzando por las formas de ocupación del espacio periurbano (necrópolis, establecimientos artesanales o lugares de culto), los vici militares establecidos a escasa distancia de los campamentos y fuertes, para seguir con los establecimientos rústicos. Sin olvidar la red de comunicaciones que articula el territorio y permite su conexión con otras regiones.

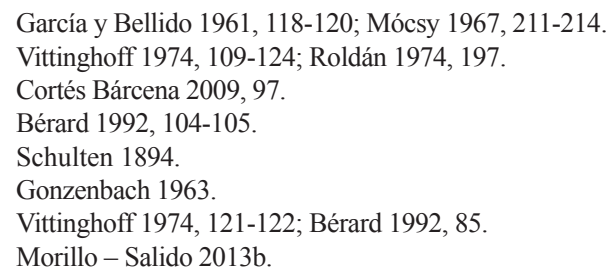




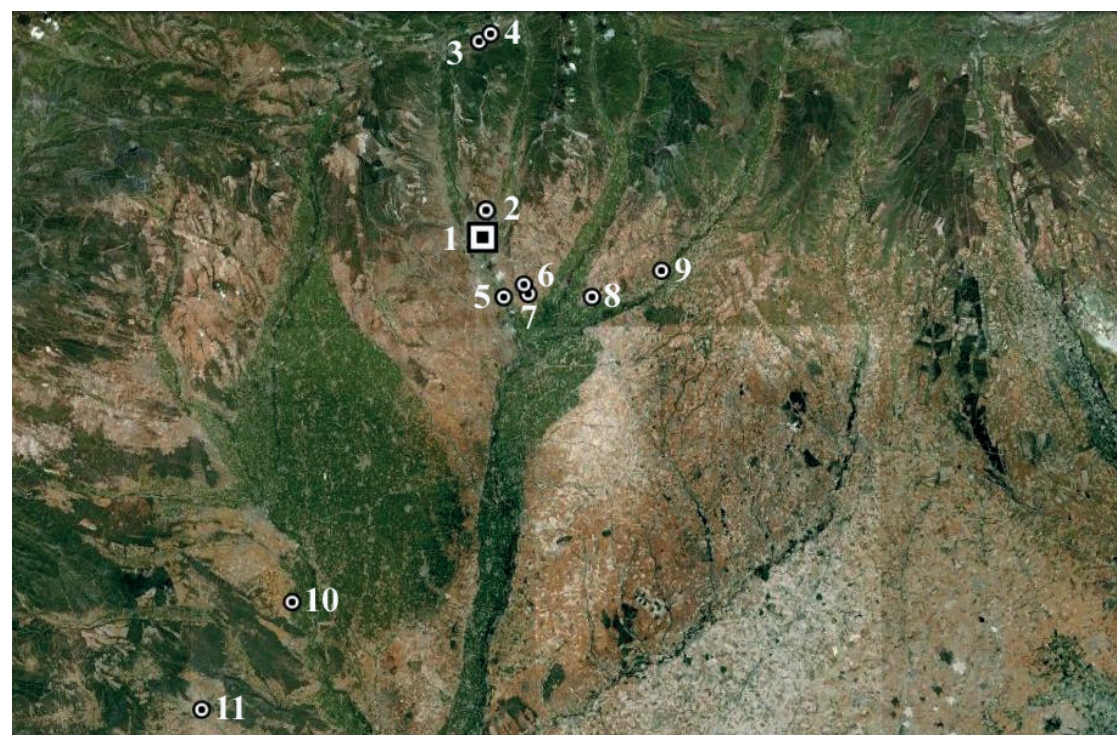

Figura 11. Dispersión de las marcas de la Legio VII gemina en el entorno de León: 1. Campamento romano de la legio VII gemina (León). 2. Villa romana de Navatejera. 3. Rabanal de Fenar. 4. Candanedo de Fenar. 5. Villa romana de Marialba. 6. Valdesogo de Arriba. 7. Valdesogo de Abajo. 8. Ciudad romana de Lancia (Villasabariego). 9. San Miguel de la Escalada. 10. Villa romana de Quintana del Marco. 11. Campamento romano de Rosinos de Vidriales (Morillo - Salido 2013).

\section{La leuga prima, un nuevo tipo de demarcación territorial de carácter militar: el ejemplo del vicus militar de Ad Legionem}

Hace algunos años, a partir del análisis de varias inscripciones de Pfaffenberg, junto al campamento de Carnuntum, Piso planteó la existencia de un nuevo tipo de demarcación militar de carácter territorial establecida a partir de una medida de longitud, la leuga. En dichos epígrafes se mencionan específicamente los términos intra leugam o intra leugam primam. ${ }^{71}$ Según este investigador sería una franja "estratégica" de territorio de un radio de una leuga, 1,5 millas $(2,2 \mathrm{~km})$, ocupado por algunas instalaciones militares (fábricas, talleres, canteras), prados, además de las propias necrópolis del campamento y la población civil que vivía junto a los muros, demarcación sobre la que la jurisdicción militar, representada por el legado, sería soberana, tanto sobre la propiedad como en el ejercicio de la justicia. La medición debía partir de la puerta del campamento, donde arrancaban las vías. La leuga (legua), término de

71 Piso 1991, 133-137 y 141, y 2003. El desarrollo de las inscripciones es muy semejante. Una de las más completas es la número 2, que recogemos íntegra a modo de ejemplo: [I(ovi) O(ptimo)] M(aximo) / [pr]o [sa]lute Imp(eratorum) / Augu[storu]m / M(arci) Aur[el(ii) A]n[t]onini / Aug(usti) [Arm(eniaci) P]art(hici) Max(imi) / et L(uci) A[u]r(elli) Ve[ri A]ug(usti) Arm(eniaci) / Pa[rt(hici)] Max[x(imi) C(ives) R(omani)] con/ sis[t]ent(es) Ka[r]nunt[i] / intra leugam p[r(imam)?] / M(arcus) Iu[l(ius) Serg(ia)] / ...in[us] d[ec(uriones) ¿m(unicipii) K(arnunti) et] / ...nu[s] ... / magi[stri] mo[ntis] / [P]ude[nte et P]ollio[ne co(n)s(ulibus)]. 
origen celta, es una medida de longitud propia de las provincias germánicas, gálicas y danubianas, verificándose a partir del siglo II d.C. gracias a la epigrafía y perdurando al menos hasta el IV. ${ }^{72}$ Su presencia epigráfica se verifica incluso en el norte de África $^{73}$ (Fig. 12). I. Piso apunta incluso que la leuga prima en este contexto militar tendría un sentido semejante el término circum, localizado en una inscripción de Xanten. ${ }^{74}$ Recientemente Gugl ha apuntado que el espacio correspondiente a la leuga o territorio bajo administración directa de la unidad militar, implicaría ciertas restricciones a los residentes, posiblemente en aspectos como la propiedad del terreno. ${ }^{75}$

Fuera de este espacio de algo más de $2 \mathrm{~km}$, las comunidades próximas (vici) pudieron gozar de cierta autonomía, derecho de propiedad sobre la tierra, motivo por el que pudieron alcanzar su estatuto municipal ${ }^{76}$ Es decir, ya no dependían desde el punto de vista jurisdiccional de la autoridad militar sino de las autoridades civiles de la provincia, aunque su propia existencia se encuentra en una estrecha relación con el vecino campamento legionario.

La existencia del espacio comprendido dentro de la primera leuga a partir del campamento legionario como territorio militar privativo se considera hoy en día como la razón que justificaría en último término la duplicidad de asentamientos satélites para la población civil en el entorno inmediato de los campamentos legionarios (dos vici militares o una cannabae epigráficamente constatada y un vicus). El progreso en la investigación arqueológica ha permitido confirmar que esta duplicidad de asentamientos es mucho más común de lo que se pensaba hace tan sólo unos años, verificándose en camp . D incias fronterizas, con una especial concentra

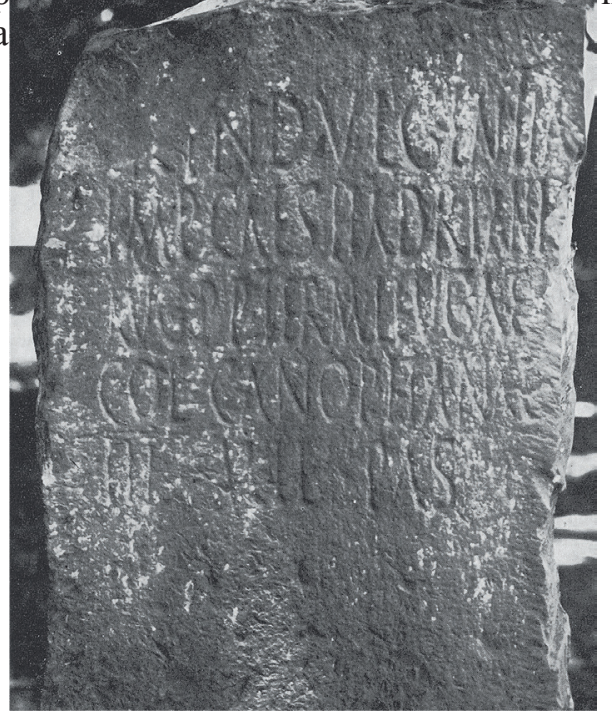

Figura 12. Hito terminal donde se menciona el límite de la leuga de la Colonia Canopita-

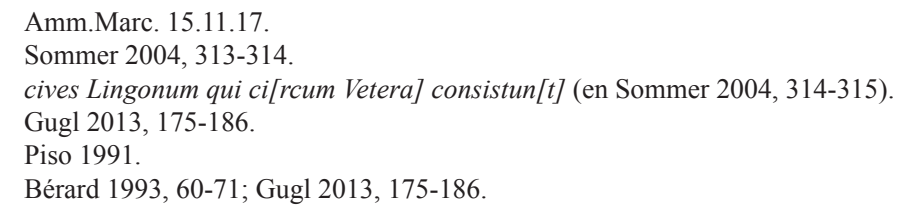




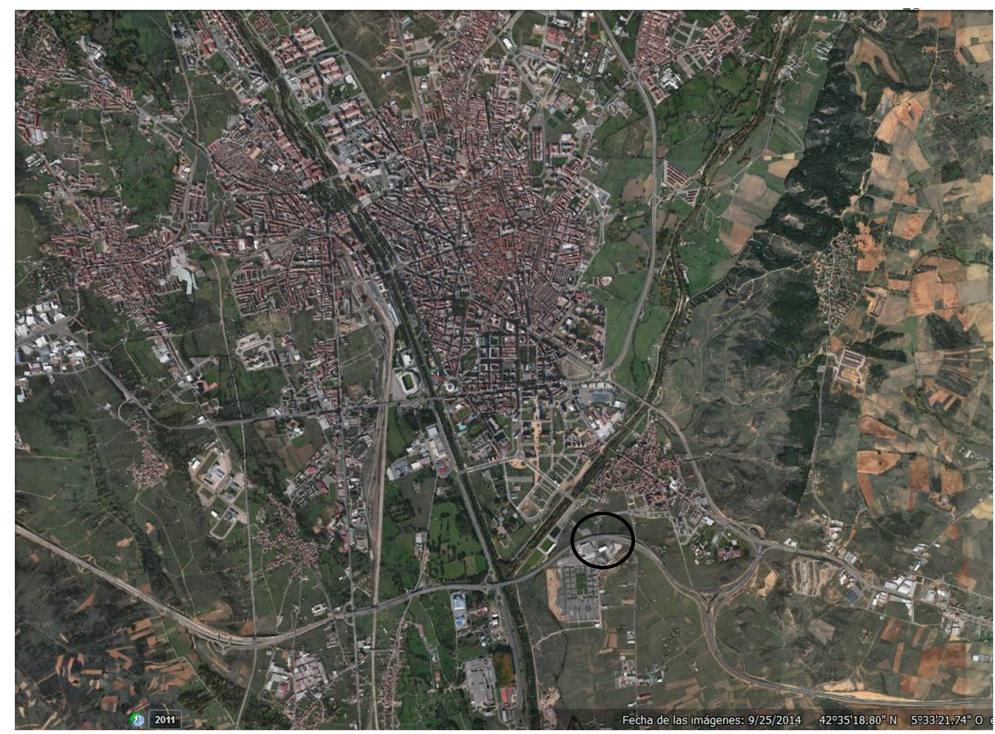

Figura 13. Situación general del yacimiento de Puente Castro en relación con la ciudad de León.

Ambos tipos de asentamientos (suburbio civil de los campamentos legionarios y vici militares) operaban también en subsistemas económicos diferentes. Entre los habitantes de las canabae o vici surgidos junto a los fosos serían más abundantes los ciudadanos romanos y el personal administrativo. Por el contrario, en los vici situados fuera de la jurisdicción militar, sujetos por lo tanto a la administración provincial, habría menos ciudadanos romanos y, a pesar de no perder de vista las posibilidades de negocio que ofrecía la población del vecino campamento, tendrían un contacto mucho mayor con el mundo rural y las actividades agropecuarias y artesanales. ${ }^{79}$

Los resultados de las intervenciones arqueológicas realizadas durante los años 2000-2001 al sureste de la ciudad de León, al otro lado del río Torío y junto al actual barrio de Puente Castro, nos han permitido identificar una nueva aglomeración secundaria o vicus, denominado Ad Legionem, surgido en estrecha relación de dependencia con el cercano campamento de la legio VII gemina (Fig. 13). ${ }^{80}$ La disposición de los edificios y la regularización de la planta de las construcciones del vicus nos informa sobre la presencia de una aglomeración polifuncional del tipo viario estructurada en manzanas o insulae rectangulares separadas por callejuelas, del modelo conocido como street-type, ribbon-type o through-road type, es decir, estructurado en torno a una calzada romana, ${ }^{81}$ el modelo más común de los vici militares del Occidente del Imperio Romano. En efecto, el complejo constructivo se hallaba limitado al este por una calle que podemos identificar con la vía $\mathrm{n}^{\circ} 1$ del Itinerario de Antonino De Italia in Hispanias, que se dirigía desde el campamento de Legio hacia la

\footnotetext{
78 Lectura: [e]x indulgentia / Imp(eratoris) Caes(aris) Hadriani / Aug(usti) p(atris) p(atriae) term(inus) leugae / col(oniae) Canopitanae / III mil(ia) pas(suum).

79 Gugl 2013, 147-172.

80 Álvarez Ordás et alii 2000-2001; Morillo 2012, 244; Morillo et alii 2014, 127.

81 Sommer 1997 y 2006, 97-102.
} 


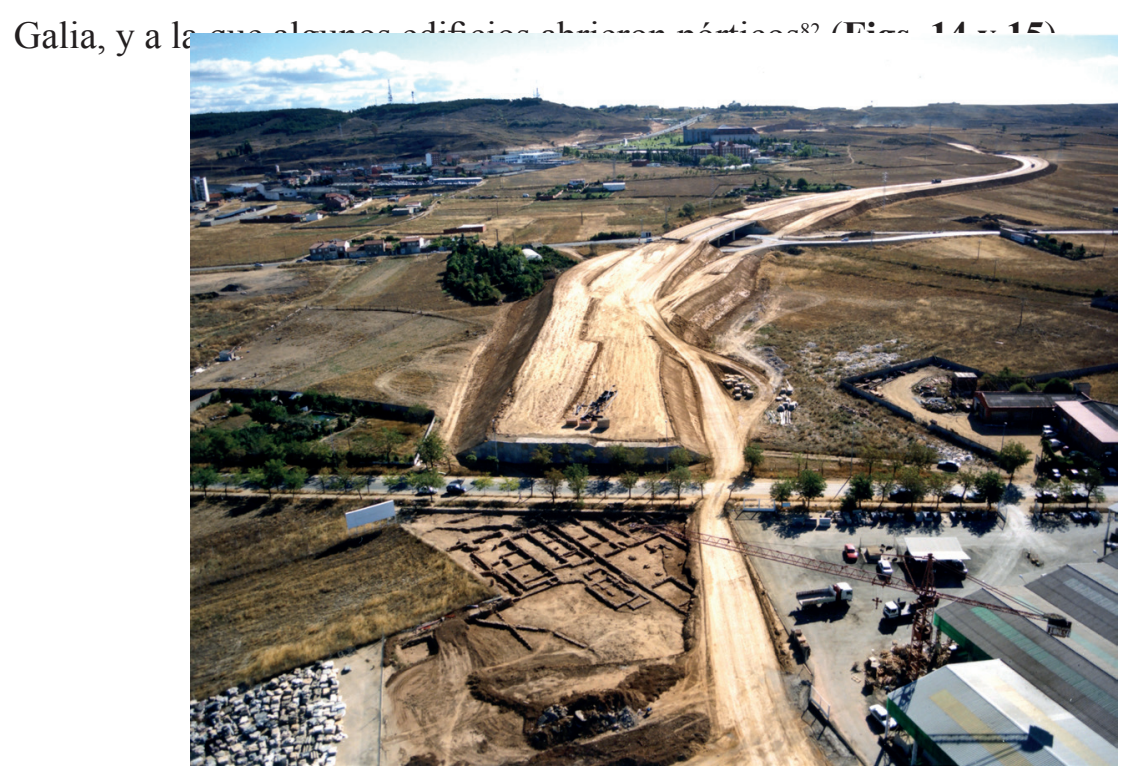

Figura 14. Vista aérea de la intersección de la carretera del Cementerio con la Ronda Sur de circunvalación, en construcción. En primer término se aprecia la segunda fase de intervención, mientras la primera se encuentra ya enterrada bajo el talud oriental del puente de la nueva Ronda Sur de circunvalación (J. C. Álvarez Ordás).

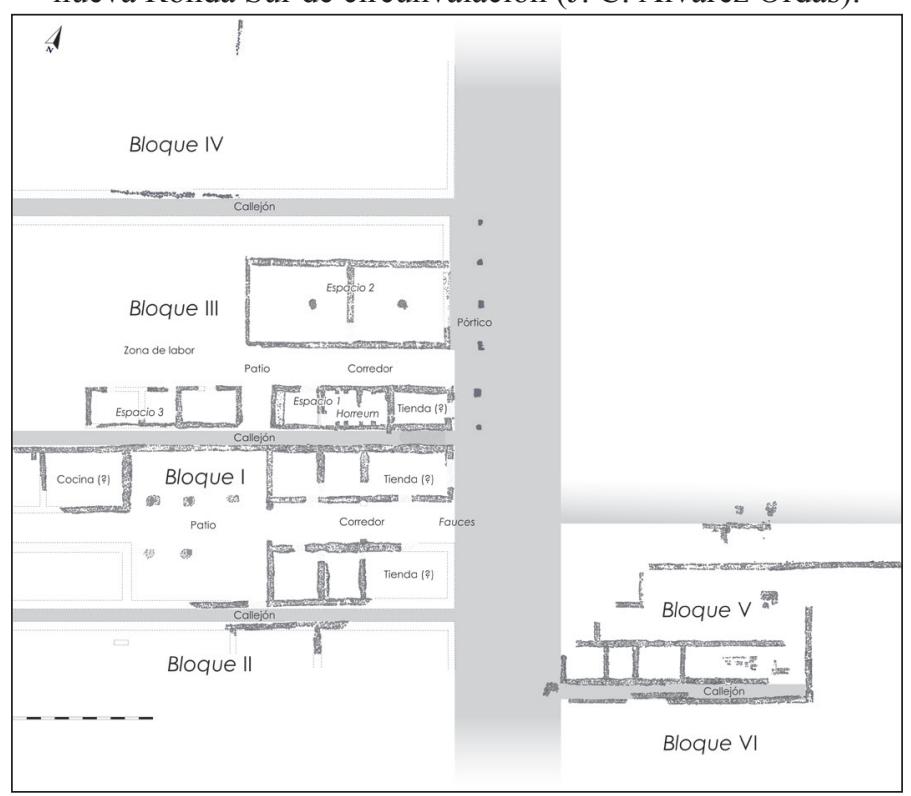

Figura 15. Primera fase constructiva del vicus militar. Propuesta interpretativa de ambos sectores. En el caso de la primera intervención es una fotointerpretación sobre fotografía aérea

82 Morillo et alii 2018, 158-160. 


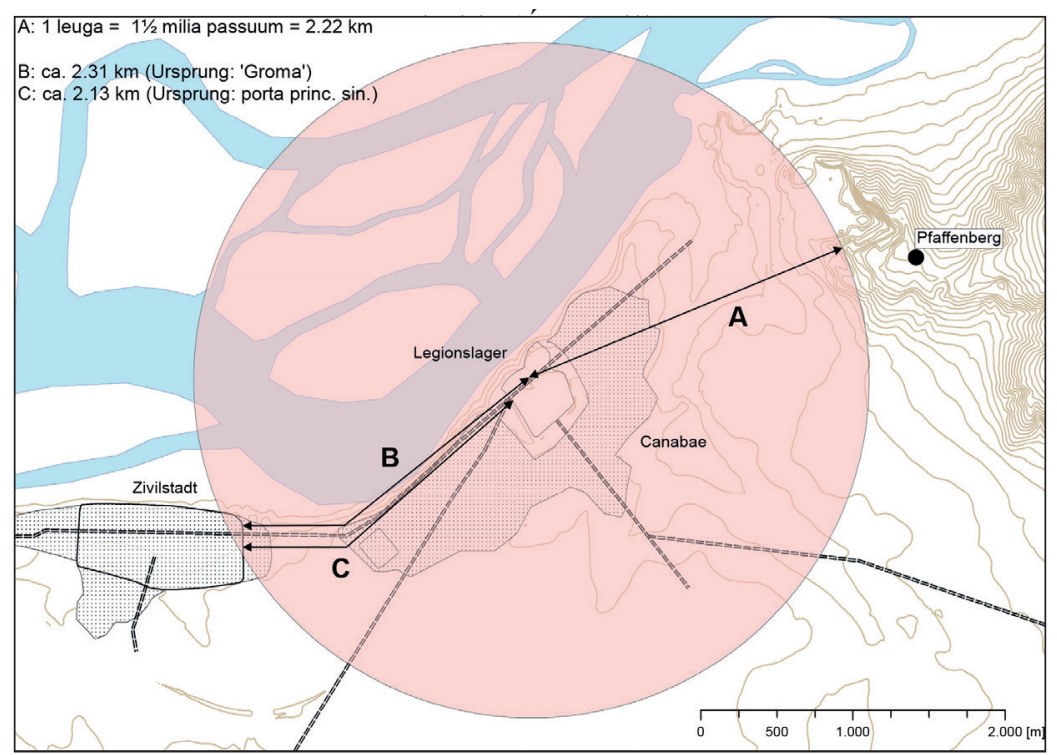

Figura 16. El campamento de Carnuntum y sus establecimientos civiles subsidiarios, con

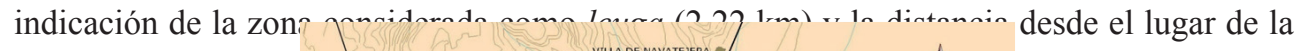

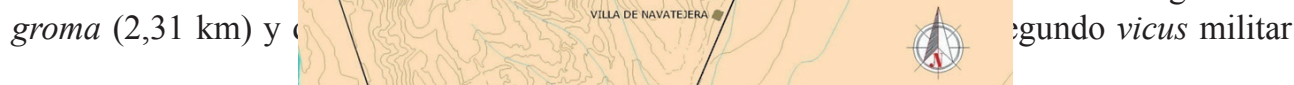

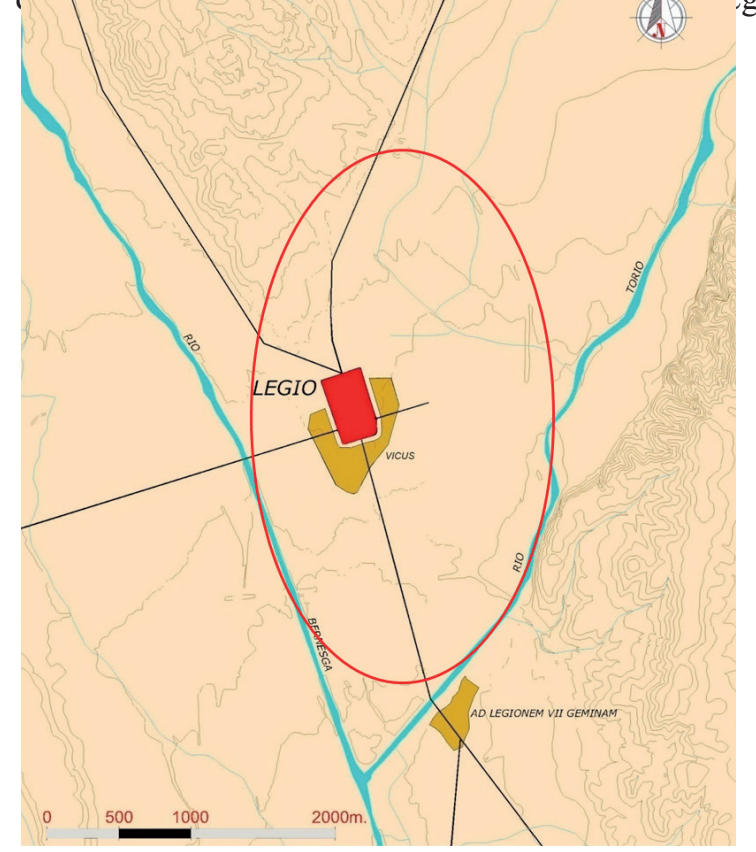

Figura 17. Posición topográfica del campamento legionario de la legio VII gemina en León 
con los asentamientos civiles subsidiarios y en relación con la red viaria. En el ángulo SE el vicus de Ad Legionem (Puente Castro). El óvalo corresponde a la posible zona de leuga (Á. Morillo).

Este segundo vicus satélite del campamento de la Legión VII Gémina responde a la misma casuística que se ha definido para campamentos como Carnuntum (Fig. 16). De nuevo en este caso nos encontramos ante una distancia de $2,2 \mathrm{~km}$ (una leuga) respecto al campamento de Legio. La población se establece ultra pontem, al otro lado del río Torío, lo que parece indicar que el curso fluvial actúa de alguna manera como límite geográfico. ${ }^{83}$

A partir de la existencia de este vicus militar satélite, cuya ubicación dista exactamente una leuga $(1,5$ millas romanas $=2,2 \mathrm{~km})$ respecto a las murallas del campamento de la legio VII, junto a las que existía un primer vicus o cannabae militar, podemos plantear la hipótesis de que también en el caso de Hispania se verificaría la existencia de la leuga aplicada a la demarcación del espacio militar respecto al civil (Fig. 17).

\section{Algunas consideraciones finales}

El progreso en la investigación de los últimos años permite avanzar en el análisis de los territorios militares en la antigua Hispania. La incorporación paulatina de nuevas regiones por parte de Roma llevó a la creación de una nueva organización territorial, que exigía una delimitación física de los territorios asignados tanto al Estado como a los nuevos municipios o civitates. Los documentos epigráficos relativos a los límites de distritos asignados a unidades militares no suelen ser muy habituales, aunque el conjunto procedente del norte de la Península Ibérica es el más numeroso de todo el Imperio. La Hispania Citerior ha proporcionado una treintena de hitos de demarcación de este tipo, constituidos por dos conjuntos principales: uno que deslinda los prata de la legio IIII Macedonica respecto al ager de los municipios de derecho latino de Iuliobriga y Segisama, que se concentra en torno al valle del río Camesa, al sur de Cantabria, y al este de la provincia de Burgos; otro concerniente a la cohors IV Gallorum y datado en época de Claudio, que delimita sus tierras respecto las $\mathrm{ci}$ vitates Bedunia y Luggonum, procedente de la región de La Bañeza (León), que han generado en la bibliografía una amplia polémica tanto sobre la extensión del territorio militar, como sobre la cronología de los mismos. Se conoce asimismo otro hito de demarcación de los campos de la legio X gemina respecto a la civitas Bedunia, procedente también de la misma área que los anteriores.

En realidad, la presencia de hitos de delimitación militares forma parte de una cuestión mucho más amplia y compleja, como es la asignación de territorios a unidades del ejército. El propio vocablo prata tiene un carácter restrictivo, ya que no alude a tierras de cultivo, sino a pastos, evidentemente para los caballos y los rebaños. Como bien señala Cortés Bárcena, la primera cuestión es aclarar si el término prata es sinónimo de territorio militar, ${ }^{84}$ tal y como lo consideran autores como García y Bellido y Mócsy. Sin embargo, la mayoría (Vittinghoff, Roldán, Le Roux) se inclina hoy en día por considerar que es un término mucho más restrictivo que territorium,

Morillo et alii $2018,176$.

84 Cortés Bárcena 2013, 240-241. 
y no puede identificarse con el territorio militar en su conjunto, sino que respondería a pequeños enclaves dentro del radio de acción de la unidad militar, pero sin constituir un territorio continuo. De hecho se pone en duda la propia existencia de un amplio dominio territorial por parte de las unidades militares. No poseen personalidad jurídica diferenciada, ni se puede sostener su existencia desde el punto de vista epigráfico y arqueológico, salvo que entendamos por territorio militar un distrito que rodea a los campamentos y en el que se hace patente su influencia desde un punto de vista más económico. Sería por lo tanto más propio hablar de territorio militarizado.

Las excavaciones realizadas durante los años 2000-2001 al sureste de la ciudad de León y junto al actual barrio de Puente Castro, nos han permitido identificar una nueva aglomeración secundaria o vicus, denominado Ad Legionem, surgido en estrecha relación de dependencia con el cercano acantonamiento de la legio VII gemina, situada al otro lado del río Torío y a $2,2 \mathrm{~km}$ de distancia de los castra.

A partir de la ubicación de este segundo vicus satélite, exactamente a una leuga del campamento de León, podemos plantear la hipótesis de que también en el caso de Hispania, al igual que en las provincias danubianas, las Galias, Britania o el norte de África, se verifica la existencia de la leuga, que Piso define a partir de los testimonios epigráficos como franja "estratégica" de territorio de un radio de 1,5 millas $(2,2$ $\mathrm{km}$ ), ocupado por algunas instalaciones militares (fábricas, talleres, canteras), prados, además de las propias necrópolis del campamento y la población civil que vivía junto a los muros, demarcación sobre la que la jurisdicción militar, representada por el legado, sería soberana, tanto sobre la propiedad como en el ejercicio de la justicia.

\section{Referencias bibliográficas}

Abascal, J. M. (2008): "La epigrafía de los límites de las ciudades romanas de Hispania. Una revisión", [en] J. M. Iglesias Gil (ed.), Cursos sobre el Patrimonio Histórico 12. Actas de los XVIII Cursos Monográficos sobre el Patrimonio Histórico, Santander, 77-93.

Álvarez Ordás, J. C. - Rodríguez González, P. - Martínez Murciego, N. (2000-2001): "Instrumental médico procedente de la excavación del yacimiento de época romana de la carretera del cementerio. Puente Castro. León. Una aproximación", Lancia 4, 141-158.

Álvarez Santos, J. A. (2005): La terra sigillata en Cantabria: los fondos del Museo Provincial de Prehistoria y Arqueología de Cantabria y del Museo Arqueológico Nacional, Santander.

Ariño, E. (2005): "La Hispania Citerior occidental y la Lusitania septentrional entre Augusto y los Flavios: el ager per extremitatem mensura comprehensus", [en] L'Aquitanie et l'Hispanie septentrional à l'époque julio-claudienne, Organisation et exploitation des espaces provinciaux. Colloque Aquitania (=Aquitania Suppl. 13), Bordeaux, 95-112.

Ariño, E. - Gurt, J. M. - Palet, J. M. (2004): El pasado presente. Arqueología de los paisajes en la Hispania romana (=Universidad de Salamanca. Acta Salmanticensia. Estudios Geográficos \& Históricos 122), Salamanca.

Bérard, F.

(1992): “Territorium legionis: camps militaires et agglomérations civiles aux premiers siècles de 1'empire", Cahiers du Centre Gustav Glotz 3, 75-105 (https://doi. 
org/10.3406/ccgg.1992.1349).

(1993): "Vikani, kanabenses, consistenses: remarques sur l'organisation des agglomerations militaires romaines", [en] A. Calbi - A. Donati - G. Poma (eds.), L'epigrafia del villaggio (=Epigrafia e Antichita 12), Faenza, 61-90.

Blázquez Cerrato, C. - Carretero, S. (2006): "Cronologías estratigráficas: cerámica y monedas“, [en] García-Bellido (coord.), 2006, 195-218.

Carretero, $\mathrm{S}$.

(2000): El campamento romano del ala II Flavia en Rosinos de Vidriales (Zamora). La cerámica, Madrid.

(2006): "Petavonium (Rosinos de Vidriales, Zamora). Introducción histórica y arqueológica", [en] García-Bellido (coord.), 2006, 171-194.

Carretero, S. - Romero Carnicero, $\mathrm{M}^{\mathrm{a}} \mathrm{V}$. (1996): Los campamentos romanos de Petavonium (Rosinos de Vidriales, Zamora), Zamora.

Cepeda, J. J. - Iglesias Gil, J. M. - Ruiz, A. (2008): "Territorio rural y espacio urbano en Iuliobriga", [en] J. Mangas - M. Á. Novillo (eds.), El territorio de las ciudades romanas, Madrid, 309-331.

Cortés Bárcena, C.

(2002-2003): "Epigrafía y territorio en la Hispania romana: los termini públicos", Anas 15/16, 107-126.

(2013): Epigrafia en los confines de las ciudades romanas. Los termini publici en Hispania, Mauretania y Numidia (=L'Erma di Bretschneider. Hispania Antigua. Serie Histórica 7), Roma.

Descosido, M. (1982): “Término augustal de la Legio X”, Tierras de León 48, 9196.

Fernández Ochoa, C. - Morillo, Á. - Gil Sendino, F. (2012): "El Itinerario de Barro: cuestiones de autenticidad y lectura", Zephyrus 70, 153-181.

Fernández Vega, P. - Bolado del Castillo, R. - Callejo Gómez, J. - Mantecón Callejo, L. (2012): "Un nuevo término augustal del ager Iuliobrigensium", AEspA 85, 267-271 (http://dx.doi.org/10.3989/aespa.085.012.015).

García-Bellido, M ${ }^{\mathrm{a}}$ P. (coord.), (2006): Los campamentos romanos en Hispania (27 a.C.-192 d.C.). El abastecimiento de moneda (=Anejos de Gladius 9), Madrid.

García y Bellido, A. (1961): "El 'Exercitus Hispanicus' desde Augusto a Vespasiano", AEspA 34, 114-160.

Gómez-Pantoja, J. (2011): "Un nuevo terminus augustalis de la Lusitania", [en] A. Sartori - A. Valvo (eds.), Identità e autonomie nel mondo romano occidentale (=Epigrafía e Antichità 29), Faenza, 291-317.

González Echegaray, J. - Solana, J. M. (1975): “La Legión IV Macedónica en España”, Hispania Antiqua 5, 151-203.

Gonzenbah, V. von (1963): "Die Verbreitung des gestempelten Ziegel der im 1. Jahrhundert n. Chr. In Vindonissa liegenden römischen Truppen", Bonner Jahrbücher 163, 76-150.

Groenman-van Waateringe, W. (1997): "Classical authors and the diet of Roman soldiers: true or false", [en] W. Groenman-van Waateringe - B. L. van Beek - W. J. H. Willems - S. L. Wynia (eds.), Roman Frontier Studies 1995. Proceedings of the XVIth International Congress of Roman Frontier Studies (=Oxbow Monograph 91), Oxford, 261-265.

Gugl, G. (2013): "Die Carnuntiner canabae - ein Modell für römische Lager vorstädte", [en] M. Doneus - Ch. Gugl- N. Doneus, Die Canabae von Carnuntum. Eine 
Modellstudie der Erforschung römischer Lagervorstädte. Von der Luftbildprospektion zur siedlungsarchäologischen Synthese (=Der römische Limes in Österreich 47), Wien, 146-214.

Iglesias Gil, J. M. - Ruiz, A. (1998): Epigrafia romana de Cantabria (=Ausonius. PETRAE Hispaniarum 2), Santander.

Kovács, P. (2013): "Territoria, pagi and vici in Pannonia", [en] G. Alföldy - F. Kolb - W. Schmitz (eds.), Studia Epigraphica in memoriam Géza Alföldy (=Antiquitas 1), Bonn, 131-153.

Le Roux, P.

(1982): L'armée romaine et l'organisation des provinces ibériques d'Auguste a l'invasion de 409, Paris.

(1994): “Cites et territoires en Hispanie: l'epigraphie des limites", Mélanges de la Casa de Velázquez 30/1, 37-51.

Loewihsohn, E. (1963): "Una calzada y dos campamentos romanos del Conventus Asturum", AEspA 38, 26-43.

Mac Mullen, R. (1963): Soldier and Civilian in the Later Roman Empire, Cambridge. Mangas, J. (2008): "Límites exteriores e interiores del territorio de las civitates astures", [en] J. Mangas - M. Á. Novillo (eds.), El territorio de las ciudades romanas, Madrid, 83-106.

Mañanes, T. - Solana, J. Ma (1985): Ciudades y vías romanas de la Cuenca del Duero (Castilla y León), Valladolid-Salamanca.

Martín Valls, R. - Delibes de Castro, G. - Mañanes, T. (1975): Sobre los campamentos de Petavonium (=Studia Archaeologica 36), Valladolid.

Mócsy, A.

(1953): "Das territorium legionis und die cannabae in Pannonien", Acta Archaeologica Acaemiae Scientiarum Hungaricae 3, 179-200.

(1967): “Zu den prata legionis", [en] Studien zu den militärgrenzen Roms. Vorträge des 6.Internationalen Limeskongresses in Süddeutschland (=Beihefte der Bonner Jahrbücher 19), Köln, 211-214.

(1974): "Il problema delle condizioni del suolo attribuito alle unitá militari nelle province danubiane", [en] I diritti locali nelle province romane con particolare riguardo alle condizioni giuridiche del suolo, Roma, 345-355.

Morillo, Á.

(1999): Lucernas romanas en la región septentrional de la Península Ibérica. Contribución al conocimiento de la implantación romana en Hispania (=Monographies Instrumentum 8), Montagnac.

(2000): "La legio IIII Macedonica en la Península Ibérica. El campamento de Herrera de Pisuerga (Palencia)", [en] Y. Le Bohec - C. Wolff (eds.), II Congrés de Lyon sur l'armée romaine. Les légions de Rome sous le Haut Empire, Lyon, 609-624.

(2002): "Conquista y estrategia: el ejército romano durante el periodo augusteo y julio-claudio en la región septentrional de la península ibérica", [en] Á. Morillo (coord.), Arqueología Militar Romana en Hispania (=Anejos de Gladius 5), Madrid, 67-94.

(2006): “Abastecimiento y producción local en los campamentos de la región septentrional de la Península Ibérica", [en] Á. Morillo (ed.), Arqueología Militar Romana en Hispania. Producción y abastecimiento en el ámbito militar, León, 33-74.

(2008): "La implantación militar romana en el territorio de Cantabria durante el Alto Imperio", [en] J. R. Aja - M. Cisneros - J. L. Ramírez (eds.), Los cántabros 
en la Antigüedad. La historia frente al mito, Santander, 142-154.

(2012): "Investigación científica y arqueología urbana en la ciudad de León”, [en] J. Beltrán - O. Rodríguez (eds.), Hispaniae urbes. Investigaciones arqueológicas en ciudades históricas (=Universidad de Sevilla. Serie Historia y Geografía 203), Sevilla, 211-256.

Morillo, A. - García Marcos, V. - Salido, J. - Durán Cabello, R. (2018): “El vicus militar de Ad Legionem (Puente Castro, León). Las intervenciones arqueológicas de los años 2000-2001", Spal 27/1, 145-183 (http://dx.doi.org/10.12795/spal. 2018i27.06).

Morillo, Á. - Pérez González, C. - Illarregui, E. (2006): “Asentamientos militares de Herrera de Pisuerga: introducción histórica y arqueológica”, [en] García-Bellido (ed.), 2006, 305-323.

Morillo, Á. - Salido, J.

(2013): "Marcas militares sobre producciones latericias en Hispania: nuevas consideraciones sobre su origen y difusión", Gerion 31/1, 287-329 (http://dx.doi. org/10.5209/rev_GERI.2013.v31.43623).

(2013b): "Material constructivo latericio procedente del campamento de la legio VII gemina en León. La intervención arqueológica en Puerta Obispo", Lucentum 32, 147-170 (http://dx.doi.org/10.14198/LVCENTVM2013.32.07).

Morillo, Á. - Salido, J. - Durán, R. (2014): "Aglomeraciones secundarias de carácter militar en Hispania", [en] Homenaje a la Profesora Katia Galán Saunier (=Anejos de CuPAUAM 1), Madrid, 117-131 (http://dx.doi.org/10.15366/anejos. galan2014).

Orejas, A. (2002): "El territorio de las civitates peregrinas en los tratados de agrimensura. Las civitates del noroeste hispano", Habis 33, 389-406.

Pérex Agorreta, M. J. - Rodríguez Morales, J. (2011): "Término augustal hallado en Lekunberri (Navarra): estudio preliminar", Trabajos de Arqueología Navarra 23, 5-19.

Piso, I.

(1991): "Die Inschriften vom Pfaffenberg und der Bereich der Canabae legionis", Tyche 6, 131-169.

(1995): "Eine Parallele zwischen den Praetoria der Statthalter in Carnuntum und in Apulum", Carnuntum Jb 1993/94, 203-209.

(2003): Die Inschriften. Das Heiligtum des Jupiter Optimus Maximus auf dem Pfaffenberg/Carnuntum 1 (=Der römische Limes in Österreich 41/1), Wien.

Rabanal, M. A. - García Martínez, S. (2001): Epigrafía romana de la provincia de León: revisión y actualización (=Universidad de León. León, Historia y Sociedad 8), León.

Roldán, J. M. (1974): Hispania y el ejército romano. Contribución a la historia social de la España antigua, Salamanca.

Schulten, A. (1894): "Das territorium legionis", Hermes 29, 481-516.

Solana, J. M. (1981): Los cántabros y la ciudad de Iuliobriga, Santander.

Sommer, C. S.

(1997): "Kastellvicus und Kastell- Mödell für die Canabae legionis?", Gesellschaft Pro Vindonissa 1997, 41-52.

(2004): “Intra Leugam, Canabae, Kastellvici und der Obergermaenisch-Raetische Limes", [en] L. Ruscu - C. Ciongrandi - R. Ardevan (eds.), Orbis antiquus, Studia in honorem Ioannis Pisonis, Cluj-Napoca, 312-321. 
(2006): "Military vici in Roman Britain revisited", [en] R. J. A. Wilson (ed.), Romanitas: essays on Roman archaeology in honour of Sheppard Frere on the occasion of his ninetieth birthday, Oxford, 95-145.

TIR K-29: Tabula Imperii Romani. Hoja K-30: Porto, Madrid, 1991.

TIR K-30: Tabula Imperii Romani. Hoja K-30: Madrid, Madrid, 1993.

Vittinghoff, F. (1974): "Das problem des "militärterritoriums" in der vorseverischen Kaiserzeit", [en] I diritti locali nelle province romane con particolare riguardo alle condizioni guiridiche del suolo, Roma, 109-124.

Wahl, J. (1984): "Ein Ziegelstempel der legio X gemina aus dem Alenkastell bei Rosinos de Vidriales (Prov. Zamora)", Madrider Mitteilungen 25, 72-78.

Zienkiewicz, J. D. (1993): "Excavations in the scamnum tribunorum at Caerleon: the Legionary Museum Site 1983-85”, Britannia 24, 27-85 (http://dx.doi. org/10.2307/526725). 